\title{
Protein S100-Z
}

National Cancer Institute

\section{Source}

National Cancer Institute. Protein S100-Z. NCI Thesaurus. Code C113560.

Protein S100-Z (99 aa, 116 kDa) is encoded by the human S100Z gene. This protein plays a role in calcium ion binding. 